\title{
Implementation and evaluation of the five-level emergency triage (emergency severity index tool): A hospital-based, prospective, observational study
}

\author{
Harish Kodisiddaiah Shivanna* ${ }^{\mathbb{D}}$, Aruna Chala Ramesh ${ }^{\mathbb{D}}$, Keshava Murthy M Rangaswamy \\ Department of Emergency Medicine, Ramaiah Medical College, Rajiv Gandhi University of Health Sciences (RGUHS), \\ Bangalore, Karnataka, India
}

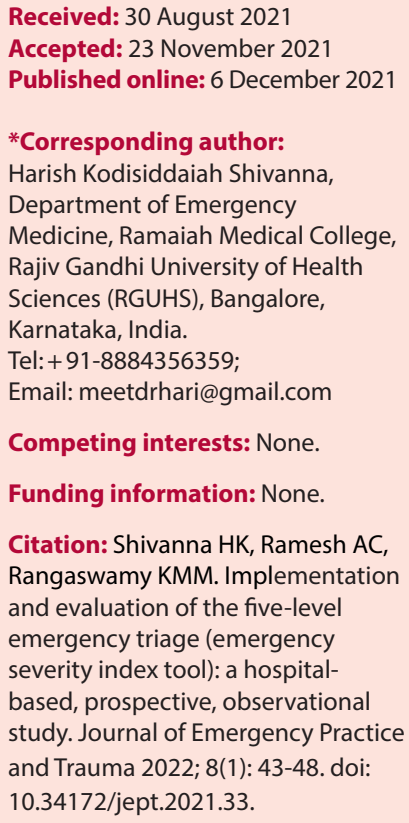

\begin{abstract}
Objective: To implement the 5-level Emergency Severity Index (ESI) triage tool into nursing practice in the emergency department (ED) and validate it with a population-based cohort using hospitalization and length of stay (LOS) as outcome measures.

Methods: The study included 850 patients, irrespective of age and gender, reporting to the ED of a tertiary care hospital. Each patient was assessed by the triage nurse as per the 5-level ESI triage tool and categorized. The number and type of resources used by the patient, LOS in the ED and the outcome were noted. Data were statistically analyzed by using RStudio Team software, 2015. A $P$ value of $<0.05$ was considered to be statistically significant.

Results: The majority of patients belonged to ESI-4 (46.82\%), followed by ESI-1 (19.41\%), ESI-2 (17.06\%), ESI-3 (10.35\%), and ESI-5 (6.35\%). In most patients, the LOS in the ED was $<120$ minutes $(55.65 \%)$. ESI showed a statistically significant association with all the clinical characteristics, as well as resources used, interventions needed, maximum time allowed before initiating physician assessment, duration of stay in ED, and patient outcomes $(P=0.000)$. ESI was found to have a sensitivity of $100 \%$ and specificity of $78 \%$.

Conclusion: $E S I$ is a useful and valid tool for the emergency triage and has the potential to become the standard triage acuity assessment in EDs in India.

Keywords: Triage, Length of stay, cohort
\end{abstract}

\section{Introduction}

Triage refers to the preliminary clinical assessment system that helps to sort and prioritize incoming patients based on how they can safely wait for a medical screening examination and treatment $(1,2)$. This ensures that the patients with the most urgent need (the highest triage acuity level) are treated first. Triage becomes particularly important in the setting of resource constraints, in terms of hospital beds, trained staff, and functioning equipment $(1,2)$. Triage data is also used by health insurers to evaluate reimbursement claims, and by authorities to establish public health priorities, necessitating the use of a reliable, accurate and valid triage acuity rating system $(1,2)$. However, the existing emergency triage methods have certain limitations, especially in the identification of non-urgent cases that may be referred elsewhere $(1,3,4)$. Undertriage leaves the patient at risk for deterioration while waiting. Overtriage exploits the scarce resources, limiting their availability for another patient in greater need of immediate care (2).

Emergency Severity Index (ESI) is a 5-level emergency triage instrument that is based on an expanded conceptual model evaluating the patient's medical urgency as well as the expected resources needed for treatment $(1,2)$. This maximizes the efficiency of patient streaming (getting the right patient to the right resources at the right place and the right time), thus reducing over-crowding (2). Various studies have found ESI to be a rapid, reproducible, valid, accurate, consistent and easy-to-use algorithm that reduces inter-rater subjectivity in triage decision making (2,5-9). This tool also facilitates communication of patient acuity more effectively and objectively (2). Also, it can be employed for all ages, including pediatric, adult and geriatric population $(1,10-13)$. However, some researchers 
argue that ESI has limited sensitivity (42\%) and merely predicts the need for hospitalization as a crude measure of outcome $(1,13)$.

Hence, the present research was aimed to implement this 5-level emergency triage algorithm, the ESI tool, into nursing practice and validate it with a population-based cohort using hospitalization and length of stay (LOS) as outcome measures.

\section{Methods}

This hospital-based, prospective, observational study was conducted at the Department of Emergency Medicine at a tertiary hospital for a period of one year from September 2015 to September 2016, after obtaining ethical clearance from the Institutional Review Board (IRB). The IRB waived the requirement for written informed consent. A minimum sample size of 337 patients was calculated for a relative precision of $5 \%$ and confidence interval of $95 \%$, based on the study by Wuerz et al (1). The study included 850 patients, irrespective of age and gender, reporting to the emergency department (ED) at this hospital. Patients with incomplete $\mathrm{ED}$ evaluation (i.e., walkout or those who left against medical advice before initial evaluation) and those seeking routine care at ED (re-dressing, suture removal) were excluded. Each included patient was initially assessed by the triage nurse in the triage area of the $\mathrm{ED}$, as per the 5-level ESI triage algorithm (Figure 1) (2,3). ESI uses a combination of patient's presenting problem, age, general appearance, physiological observations, AVPU (Alert, Verbal, Painful, Unresponsive) scale findings, vital signs (wherever time permitted), and mental status/neurologic vital signs (if indicated) to define the urgency level rating for that patient. A corresponding triage-scale color-sticker was placed on the patient's file, depending on the period within which that patient required medical assessment and treatment to be initiated. Accordingly, emergency care was initiated. Any patient marked ESI-1 or ESI-2 'red' was critical and required immediate resuscitation. Patients marked ESI-3 'yellow' were at moderate risk and required urgent care. ESI-4 or ESI-5 'green' labelling implied lower risk and non-urgent need for care. This was followed by definitive care. The number and type of resources used by the patient, LOS in the ED and outcome of the patient following ESI triage were noted.

Data were compiled and analyzed by using statistical software RStudio Team 2015. Measurements of continuous variables were expressed as mean \pm standard deviation and those of categorical variables were presented in number (\%) format. Chi-square test was used to assess the significance of study parameters on categorical scale. Receiver operating curve (ROC) was employed to determine the sensitivity and specificity of ESI. A $P$ value of $<0.05$ was considered to be statistically significant.

\section{Results}

The study consisted of 850 patients, aged between 0.1-

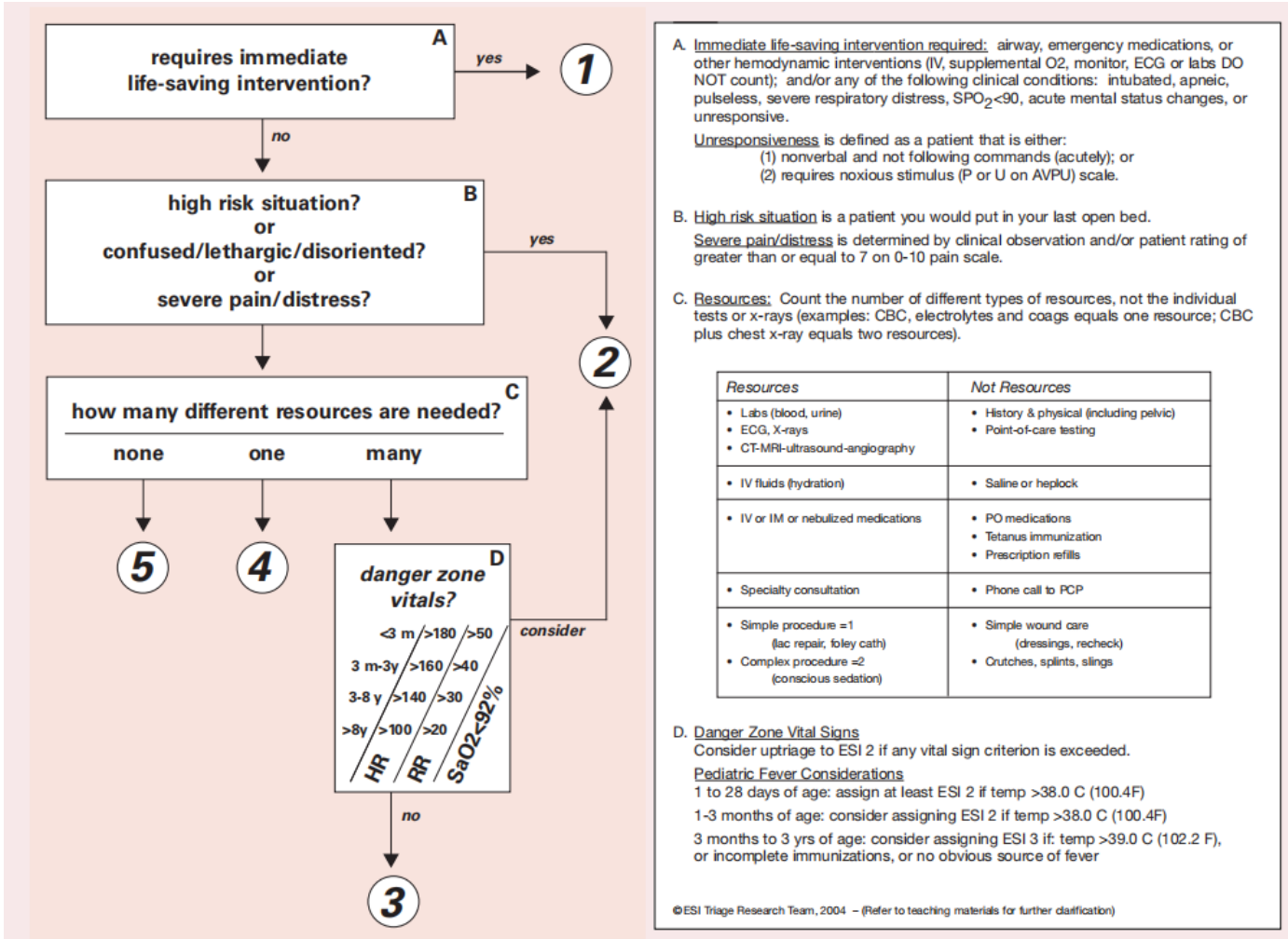

CESI Triage Research Team, 2004. Reproduced with permission.

Figure 1. Emergency Severity Index triage algorithm. 
88 years, with a $\mathrm{M}: \mathrm{F}=1.4: 1$, belonging mostly to the age group of 31-40 years. Of these, 833 (98\%) patients were triaged immediately, while the remaining $17(2 \%)$ patients were triaged within 10 minutes. Table 1 presents the frequency distribution of demographic and clinical characteristics. Most patients used only one resource (65.06\%). Laboratory resources were the most utilized resources $(25.41 \%)$. Majority of the patients belonged to ESI-4 (46.82\%) followed by ESI-1 (19.41\%), ESI-2 (17.06\%), ESI-3 (10.35\%), and ESI-5 (6.35\%). Most of the patients were seen by the emergency physicians within 30-45 minutes (ESI-4) (43.53\%) and by the ERC within 90 minutes (ESI-4) (46.47\%). Majority of the patients were admitted from ED within $<120$ minutes (84.47\%). In addition, $546(64.2 \%)$ patients got admitted to the wards or the intensive care unit (ICU) and 285 (33.53\%) patients got discharged, while 19 patients $(2.24 \%)$ died. Table 2 shows the mean values of various characteristics. The mean oxygen saturation was $92.79 \pm 7.11 \%$.

Table 3 summarizes the association of ESI with clinical characteristics. ESI showed a statistically significant association with all clinical characteristics, including number and type of resources used, emergency care initiated, maximum time allowed before initiating physician (EP/ERC) assessment, duration of stay in the $\mathrm{ED}$, and patient outcomes $(P=0.000)$.

Figure 2 presents the ROC for ESI. Table 4 depicts the area under ROC (AUROC) for ESI comparing between the positive actual state group and negative actual state group. For ESI, AUROC was 1.00, which meant 100\% classification rate. Accordingly, ESI was found to have a sensitivity of $100 \%$ and specificity of $78 \%$.

\section{Discussion}

This study was conducted to implement the 5-level ESI triage algorithm tool in the ED into nursing practice and validate it with a population-based cohort using hospitalization and LOS as outcome measures. It was found to be useful in streamlining ED operations and efficiently manage ED resources.

A gender distribution similar to the present study was seen by Baumann and Strout (58\% males), but not by Tanabe et al $(46 \%$ males) $(14,15)$. Wuerz et al found the median age of the patients to be 40 years, similar to the present study where nearly $51 \%$ of the patients were up to 40 years of age and about $49 \%$ were older. In the present study, ESI also showed a statistically significant association with age in males $(P=0.011)$, but not in females $(P=0.276)$.

The ESI does not mandate specific time standards within which patients must be triaged by the nurse and it is up to the individual institution to determine a policy. Frequently, there may be discord between the institutional policy and the flow of patient care process and ESI triage level (2). In the present research, $98 \%$ of patients were triaged immediately, while $2 \%$ of patients were triaged within 10
Table 1. Frequency distribution of Demographic and clinical characteristics $(\mathrm{N}=850)$

\begin{tabular}{|c|c|c|c|}
\hline \multicolumn{2}{|l|}{ Characteristic } & \multirow{2}{*}{$\begin{array}{c}\begin{array}{c}\text { No. of } \\
\text { patients }\end{array} \\
13\end{array}$} & \multirow{2}{*}{$\begin{array}{c}\text { Percent } \\
1.53\end{array}$} \\
\hline \multirow{10}{*}{ Age group (y) } & $<1$ & & \\
\hline & $1-10$ & 46 & 5.41 \\
\hline & $11-20$ & 58 & 6.82 \\
\hline & $21-30$ & 112 & 13.18 \\
\hline & $31-40$ & 206 & 24.24 \\
\hline & $41-50$ & 149 & 17.53 \\
\hline & $51-60$ & 125 & 14.70 \\
\hline & $61-70$ & 79 & 9.30 \\
\hline & $71-80$ & 48 & 5.65 \\
\hline & $81-90$ & 14 & 1.64 \\
\hline \multirow{2}{*}{ Gender } & Male & 494 & 58.12 \\
\hline & Female & 356 & 41.88 \\
\hline \multirow{2}{*}{$\begin{array}{l}\text { Time taken for } \\
\text { triaging in minutes }\end{array}$} & Immediately & 833 & 98 \\
\hline & Within $10 \mathrm{~min}$ & 17 & 2 \\
\hline \multirow{4}{*}{ AVPU scale } & Alert & 688 & 80.94 \\
\hline & Verbal & 52 & 6.12 \\
\hline & painful & 47 & 5.53 \\
\hline & Unresponsive scale & 63 & 7.41 \\
\hline \multirow{3}{*}{$\begin{array}{l}\text { Number of } \\
\text { resources used }\end{array}$} & None & 89 & 10.47 \\
\hline & 1 & 553 & 65.06 \\
\hline & $>1$ & 208 & 24.47 \\
\hline \multirow{7}{*}{$\begin{array}{l}\text { Type of resources } \\
\text { used }\end{array}$} & None & 96 & 11.30 \\
\hline & Laboratory resources & 216 & 25.41 \\
\hline & Radiology resources & 197 & 23.18 \\
\hline & $\begin{array}{l}\text { Intravenous/Intramuscular } \\
\text { medications }\end{array}$ & 67 & 7.88 \\
\hline & Specialty consultation & 47 & 5.53 \\
\hline & Procedural resources & 24 & 2.82 \\
\hline & Multiple resources & 203 & 23.88 \\
\hline \multirow{5}{*}{ ESI } & $\begin{array}{l}\text { Immediately life } \\
\text { threatening (ESI-1) }\end{array}$ & 165 & 19.41 \\
\hline & $\begin{array}{l}\text { Imminently life threatening } \\
(\mathrm{ESI}-2)\end{array}$ & 145 & 17.06 \\
\hline & Moderate risk (ESI-3) & 88 & 10.36 \\
\hline & $\begin{array}{l}\text { Low risk, semi urgent } \\
\text { (ESI-4) }\end{array}$ & 398 & 46.82 \\
\hline & $\begin{array}{l}\text { Lower risk, non-urgent } \\
\text { (ESI-5) }\end{array}$ & 54 & 6.35 \\
\hline \multirow{3}{*}{$\begin{array}{l}\text { Emergency care } \\
\text { initiated }\end{array}$} & $\begin{array}{l}\text { Definitive airway } \\
\text { intervention }\end{array}$ & 168 & 19.76 \\
\hline & Ventilation support & 143 & 16.82 \\
\hline & $\begin{array}{l}\text { Hemodynamic } \\
\text { interventions (haemorrhage } \\
\text { control) }\end{array}$ & 539 & 63.42 \\
\hline \multirow{5}{*}{$\begin{array}{l}\text { Maximum time } \\
\text { for emergency } \\
\text { physician review }\end{array}$} & ESI-1 (immediate) & 172 & 20.24 \\
\hline & ESI-2 (within $10 \mathrm{~min}$ ) & 143 & 16.82 \\
\hline & ESI-3 (within 15-30 min) & 124 & 14.59 \\
\hline & ESI-4 (within 30-45 min) & 370 & 43.53 \\
\hline & ESI-5 (within $60 \mathrm{~min}$ ) & 41 & 4.82 \\
\hline \multirow{5}{*}{$\begin{array}{l}\text { Maximum time for } \\
\text { emergency referral } \\
\text { consultant review }\end{array}$} & ESI-1 (immediate) & 168 & 19.76 \\
\hline & ESI-2 (within $30 \mathrm{~min}$ ) & 143 & 16.82 \\
\hline & ESI-3 (within 30-60 min) & 90 & 10.59 \\
\hline & ESI-4 (within $90 \mathrm{~min}$ ) & 395 & 46.47 \\
\hline & ESI-5 (discharged) & 54 & 6.36 \\
\hline \multirow{3}{*}{$\begin{array}{l}\text { LOS in emergency } \\
\text { department (min) }\end{array}$} & $<60$ & 245 & 28.82 \\
\hline & $<120$ & 473 & 55.65 \\
\hline & $>120$ & 132 & 15.53 \\
\hline \multirow{4}{*}{ Patient outcome } & Admitted to wards & 255 & 30 \\
\hline & Admitted to ICU & 291 & 34.23 \\
\hline & Discharged & 285 & 33.53 \\
\hline & Died & 19 & 2.24 \\
\hline
\end{tabular}

Unresponsive; $L O S=$ length of stay; $I C U=$ intensive care unit. 
Table 2. Mean values of various characteristics

\begin{tabular}{lc}
\hline Characteristic & Mean \pm SD \\
\hline Heart rate (beats per minute) & $89.76 \pm 20.09$ \\
Respiratory rate (count per minute) & $23.34 \pm 6.59$ \\
Oxygen saturation $(\%)$ & $92.79 \pm 7.11$ \\
Systolic blood pressure $(\mathrm{mm} \mathrm{Hg})$ & $119.89 \pm 20.81$ \\
Diastolic blood pressure $(\mathrm{mm} \mathrm{Hg})$ & $75.17 \pm 12.49$ \\
\hline
\end{tabular}

operations. Baumann and Strout noted that $70 \%$ of their patients belonged to ESI-3 or ESI-4, compared to about $57 \%$ in the present study (14). While utilization of one or more resources was noted in $89.5 \%$ of the patients in the current study, it was noted in $75 \%$ of the cases by Wuerz et al (1). Akin to the present study, Baumann and Strout observed that ESI-3 patients used maximum resources (14). In contrast, Elshove-Bolk et al found that $92 \%$ of the

Table 3. Association of Emergency Severity Index with clinical characteristics

\begin{tabular}{|c|c|c|c|c|c|c|c|}
\hline \multirow{2}{*}{\multicolumn{2}{|c|}{ Characteristics }} & \multicolumn{5}{|c|}{ ESI } & \multirow{2}{*}{$P$ value } \\
\hline & & \multirow{2}{*}{$\begin{array}{c}\text { ESI-1 }(\mathbf{n = 1 6 5}) \\
28(16.97 \%)\end{array}$} & \multirow{2}{*}{$\frac{\text { ESI-2 }(\mathbf{n = 1 4 5})}{7(4.83 \%)}$} & \multirow{2}{*}{$\frac{\text { ESI-3 }(\mathbf{n}=\mathbf{8 8})}{0}$} & \multirow{2}{*}{$\frac{\text { ESI-4 }(\mathbf{n}=\mathbf{3 9 8})}{0}$} & \multirow{2}{*}{$\begin{array}{c}\text { ESI-5 }(\mathbf{n}=\mathbf{5 4}) \\
54(100 \%)\end{array}$} & \\
\hline \multirow{3}{*}{ Number of resources used } & None & & & & & & \multirow{3}{*}{$0.000^{*}$} \\
\hline & 1 & $80(48.48 \%)$ & $75(51.72 \%)$ & 0 & $398(100 \%)$ & 0 & \\
\hline & $>1$ & $57(34.55 \%)$ & $63(43.45 \%)$ & $88(100 \%)$ & 0 & 0 & \\
\hline \multirow{7}{*}{ Type of resources used } & None & $32(19.39 \%)$ & $10(6.9 \%)$ & 0 & 0 & $54(100 \%)$ & \multirow{7}{*}{$0.000^{*}$} \\
\hline & Laboratory & $32(19.39 \%)$ & $29(20 \%)$ & $2(2.27 \%)$ & $153(38.44 \%)$ & 0 & \\
\hline & Radiology & $44(26.67 \%)$ & $44(30.34 \%)$ & $2(2.27 \%)$ & $107(26.88 \%)$ & 0 & \\
\hline & IV/IM medications & 0 & 0 & 0 & $67(16.83 \%)$ & 0 & \\
\hline & Specialty consultation & 0 & 0 & 0 & $47(11.81 \%)$ & 0 & \\
\hline & Procedural & 0 & 0 & 0 & $24(6.03 \%)$ & 0 & \\
\hline & Multiple & $57(34.55 \%)$ & $62(42.76 \%)$ & $84(95.46 \%)$ & 0 & 0 & \\
\hline \multirow{3}{*}{ Emergency care initiated } & Definitive airway & $165(100 \%)$ & $2(1.38 \%)$ & $1(1.14 \%)$ & 0 & 0 & \multirow{3}{*}{$0.000^{*}$} \\
\hline & Ventilation support & 0 & $142(97.93 \%)$ & 0 & $1(0.25 \%)$ & 0 & \\
\hline & Hemodynamic & 0 & $1(0.69 \%)$ & $87(98.86 \%)$ & $397(99.75 \%)$ & $54(100 \%)$ & \\
\hline \multirow{5}{*}{$\begin{array}{l}\text { Maximum time for } \\
\text { emergency physician } \\
\text { review }\end{array}$} & ESI-1 & $164(99.39 \%)$ & $6(4.14 \%)$ & $1(1.13 \%)$ & $1(0.25 \%)$ & 0 & \multirow{5}{*}{$0.000^{*}$} \\
\hline & ESI-2 & 0 & $134(92.41 \%)$ & $4(4.55 \%)$ & $5(1.26 \%)$ & 0 & \\
\hline & ESI-3 & $1(0.61 \%)$ & $3(2.07 \%)$ & $80(90.91 \%)$ & $40(10.05 \%)$ & 0 & \\
\hline & ESI-4 & 0 & $2(1.38 \%)$ & $3(3.41 \%)$ & $352(88.44 \%)$ & $13(24.07 \%)$ & \\
\hline & ESI-5 & 0 & 0 & 0 & 0 & $41(75.93 \%)$ & \\
\hline \multirow{5}{*}{$\begin{array}{l}\text { Maximum time for } \\
\text { emergency referral } \\
\text { consultant review }\end{array}$} & ESI-1 & $164(99.39 \%)$ & $2(1.38 \%)$ & $1(1.14 \%)$ & $1(0.25 \%)$ & 0 & \multirow{5}{*}{$0.000^{*}$} \\
\hline & ESI-2 & 0 & $138(95.17 \%)$ & $2(2.27 \%)$ & $3(0.75 \%)$ & 0 & \\
\hline & ESI-3 & $1(0.61 \%)$ & $3(2.07 \%)$ & $82(93.18 \%)$ & $4(1.01 \%)$ & 0 & \\
\hline & ESI-4 & 0 & $2(1.38 \%)$ & $3(3.41 \%)$ & $390(97.99 \%)$ & 0 & \\
\hline & ESI-5 & 0 & 0 & 0 & 0 & $54(100 \%)$ & \\
\hline \multirow{3}{*}{$\begin{array}{l}\text { LOS in emergency } \\
\text { department (min) }\end{array}$} & $<60$ & $149(90.3 \%)$ & $40(27.59 \%)$ & $1(1.14 \%)$ & $1(0.25 \%)$ & $54(100 \%)$ & \multirow{3}{*}{$0.000^{*}$} \\
\hline & $<120$ & $16(9.7 \%)$ & $105(72.41 \%)$ & $76(86.36 \%)$ & $276(69.35 \%)$ & 0 & \\
\hline & $>120$ & 0 & 0 & $11(12.5 \%)$ & $121(30.4 \%)$ & 0 & \\
\hline \multirow{4}{*}{ Patient outcome } & Admitted to wards & 0 & 0 & $75(85.23 \%)$ & $180(45.23 \%)$ & 0 & \multirow{4}{*}{$0.000^{*}$} \\
\hline & Admitted to ICU & $146(88.48 \%)$ & $145(100 \%)$ & 0 & 0 & 0 & \\
\hline & Discharged & 0 & 0 & $13(14.77 \%)$ & $218(54.77 \%)$ & $54(100 \%)$ & \\
\hline & Died & $19(11.52 \%)$ & 0 & 0 & 0 & 0 & \\
\hline
\end{tabular}

Abbreviations: $\mathrm{ESI}=$ Emergency Severity Index; ICU = Intensive care unit; IM=Intramuscular; IV = Intravenous; $L O S=$ length of stay

$*$ Significant at $5 \%$ level of significance.

Table 4. area under receiver operating curve for Emergency Severity Index comparing between the positive actual state group and negative actual state group

\begin{tabular}{|c|c|c|c|c|c|}
\hline \multirow{2}{*}{ ESI } & AUROC & $P$ value & $95 \%$ Confidence interval & Sensitivity & Specificity \\
\hline & 1.00 & $0.000^{*}$ & $(1,1)$ & $100 \%$ & $78 \%$ \\
\hline
\end{tabular}

Abbreviations: $\mathrm{ESI}=$ Emergency Severity Index; AUROC=Area under receiver operating curve.

*Significant at $5 \%$ level of significance. 


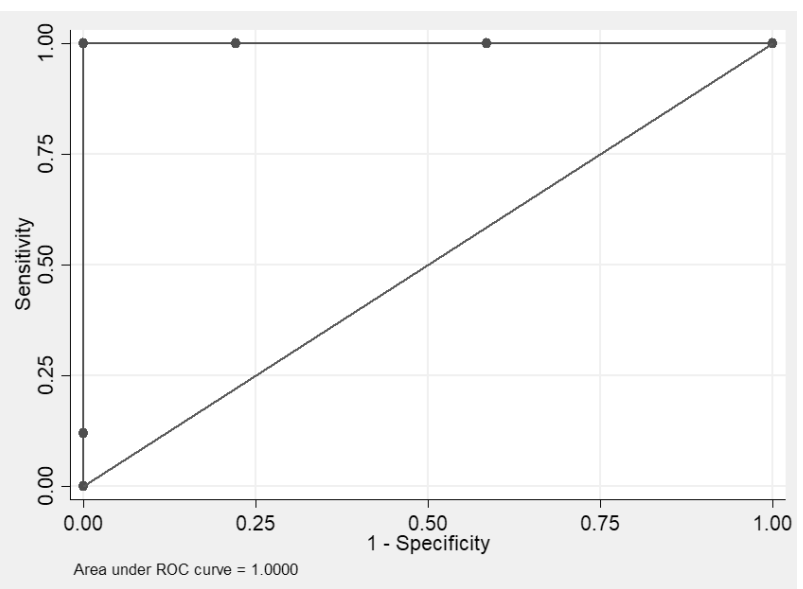

Figure 2. Receiver operating curve (ROC) for Emergency Severity Index.

resources were used by ESI-2 patients (16).

Also, the mean duration of stay at the ED was lesser in the present research compared to that noted by Wuerz et al (ranging from 266 minutes for ESI-3 to 129 minutes for ESI-5) and Baumann and Strout (ranging from 334 minutes for ESI-1 to 131 minutes for ESI-5) $(1,14)$. This was possibly because of differences in hospital census, timeliness of consultant response, and laboratory/ radiology cycle times $(1,14)$. In line with the present study, Wuerz et al, in their 2001 study, showed that 28\% of the overall and $92 \%$ of ESI-1 patient population was admitted to ICU (8). Elshove-Bolk et al found that 56\% of the patients got admitted to both ICU and wards (16). Chih et al discovered that $20.8 \%$ of patients were admitted to the ICU, while $71.1 \%$ were discharged and $0.4 \%$ faced death in the ED (17).

In the present study, the AUROC for ESI was found to be 1.00, which implied an excellent classification rate (100\%), with a confidence interval of 0.95 to 1.00 . According to Platts-Mills et al(13), ESI provided a high specificity (99\%), but a low sensitivity (42\%). This contrasts with the current research where a sensitivity of $100 \%$ and specificity of $78 \%$ was observed for ESI. Hence, this study recommends the use of ESI. It was easy and effective to implement in the emergency medicine department.

However, this research has its own limitations in being a single-center study with a limited sample size. These can be overcome by multicentric, long-term, prospective studies with a larger sample size.

\section{Conclusion}

ESI is a useful and valid tool for emergency triage and has the potential to become the standard triage acuity assessment in EDs. It helps predict the number of resources used by ED patients along with the duration of stay in the ED and the need for hospitalization. It was found easy and effective to implement the ESI Triage tool in a busy ED in Bangalore.

\section{Authors' contributions}

HKS, ACR and KMR contributed to the study design, variable selection, and revision of the study. HKS and ACR contributed to statistical analysis and revision of the study. HKS, ACR, KMK contributed to patient sampling, checklist design and study revision. All authors are affiliated to the Department of Emergency Medicine, Ramaiah Medical College,Rajiv Gandhi University of Health Sciences,Bangalore, Karnataka, India and contributed to patient sampling and filling the check lists in a timely manner.

\section{Ethical issues}

Approval for the study was granted from the ethics and research committee of the Ramaiah Medical College and Hospitals, Rajiv Gandhi University of Health Sciences, Bangalore, Karnataka, India (Ethical Code Number: STD1/EC/0420/2014).

\section{References}

1. Wuerz RC, Milne LW, Eitel DR, Travers D, Gilboy N. Reliability and validity of a new five-level triage instrument. Acad Emerg Med 2000; 7(3): 236-42. doi: 10.1111/j.15532712.2000.tb01066.x.

2. Gilboy N, Tanabe T, Travers D, Rosenau AM. Emergency Severity Index (ESI): A Triage Tool for Emergency Department Care, Version 4. Implementation Handbook 2012 Edition. AHRQ Publication No. 12-0014. Rockville, MD: Agency for Healthcare Research and Quality (AHRQ); 2011.

3. Wuerz R, Fernandes CM, Alarcon J. Inconsistency of emergency department triage. Emergency Department Operations Research Working Group. Ann Emerg Med 1998; 32(4): 431-5. doi: 10.1016/s0196-0644(98)70171-4.

4. Brillman JC, Doezema D, Tandberg D, Sklar DP, Davis KD, Simms S, et al. Triage: limitations in predicting need for emergent care and hospital admission. Ann Emerg Med 1996; 27(4): 493-500. doi: 10.1016/s0196-0644(96)70240-8.

5. Travers DA, Waller AE, Bowling JM, Flowers D, Tintinalli J. Five-level triage system more effective than three-level in tertiary emergency department. J Emerg Nurs 2002; 28(5): 395-400. doi: 10.1067/men.2002.127184.

6. Eitel DR, Travers DA, Rosenau AM, Gilboy N, Wuerz RC. The emergency severity index triage algorithm version 2 is reliable and valid. Acad Emerg Med 2003; 10(10): 1070-80. doi: 10.1111/j.1553-2712.2003.tb00577.x.

7. Worster A, Gilboy N, Fernandes CM, Eitel D, Eva K, Geisler $\mathrm{R}$, et al. Assessment of inter-observer reliability of two fivelevel triage and acuity scales: a randomized controlled trial. CJEM 2004; 6(4): 240-5. doi: 10.1017/s1481803500009192.

8. Wuerz R. Emergency severity index triage category is associated with six-month survival. ESI Triage Study Group. Acad Emerg Med 2001; 8(1): 61-4. doi: 10.1111/ j.1553-2712.2001.tb00554.x.

9. Singer RF, Infante AA, Oppenheimer CC, West CA, Siegel B. The use of and satisfaction with the Emergency Severity Index. J Emerg Nurs 2012; 38(2): 120-6. doi: 10.1016/j. jen.2010.07.004. 
10. Travers DA, Waller AE, Katznelson J, Agans R. Reliability and validity of the emergency severity index for pediatric triage. Acad Emerg Med 2009; 16(9): 843-9. doi: 10.1111/j.1553-2712.2009.00494.x.

11. Durani Y, Brecher D, Walmsley D, Attia MW, Loiselle JM. The Emergency Severity Index version 4: reliability in pediatric patients. Pediatr Emerg Care 2009; 25(11): 751-3.

12. Baumann MR, Strout TD. Triage of geriatric patients in the emergency department: validity and survival with the Emergency Severity Index. Ann Emerg Med 2007; 49(2): 234-40. doi: 10.1016/j.annemergmed.2006.04.011.

13. Platts-Mills TF, Travers D, Biese K, McCall B, Kizer S, LaMantia M, et al. Accuracy of the Emergency Severity Index triage instrument for identifying elder emergency department patients receiving an immediate life-saving intervention. Acad Emerg Med 2010; 17(3): 238-43. doi: 10.1111/j.1553-2712.2010.00670.x.
14. Baumann MR, Strout TD. Evaluation of the Emergency Severity Index (version 3) triage algorithm in pediatric patients. Acad Emerg Med 2005; 12(3): 219-24. doi: 10.1197/j.aem.2004.09.023.

15. Tanabe P, Gimbel R, Yarnold PR, Kyriacou DN, Adams JG. Reliability and validity of scores on The Emergency Severity Index version 3. Acad Emerg Med 2004; 11(1): 59-65. doi: 10.1197/j.aem.2003.06.013.

16. Elshove-Bolk J, Mencl F, van Rijswijck BT, Simons MP, van Vugt AB. Validation of the Emergency Severity Index (ESI) in self-referred patients in a European emergency department. Emerg Med J 2007; 24(3): 170-4. doi: 10.1136/ emj.2006.039883.

17. Chi $\mathrm{CH}$, Huang CM. Comparison of the Emergency Severity Index (ESI) and the Taiwan Triage System in predicting resource utilization. J Formos Med Assoc 2006; 105(8): 617-25. doi: 10.1016/s0929-6646(09)60160-1. 